\title{
Development of Lab Test Mode to Estimate Performance Drop of Brake Pads Base on Circuit Test Results
}

\author{
Tae Kwan Son ${ }^{1)}$, Sung Pil Jung ${ }^{2)}$, Kyung Seok Sim ${ }^{2)}$, Hee Bum Choi ${ }^{3)}$ and Jeong Ho Yu ${ }^{3)}$ \\ ${ }^{1)}$ Department of Mechanical and Automotive Engineering, Keimyung University, 1905, Dalgubeol- \\ daero, Dalseo-gu, Daegu, 42601, Republic of Korea. \\ 2)Premium Vehicle R\&D Center, Korea Automotive Technology Institute, 46, F1-ro, Samho-eup, \\ Yeongam-gun, Jeollanam-do, 8463, Republic of Korea. \\ ${ }^{3)}$ Frixa Co. Ltd, 1, Bongnak-gil, Byeollyang-Myeon, Sunchon-si, Jeollanam-do, 58032, Republic of \\ Korea.
}

\begin{abstract}
This paper presents the systematical approach to generate lab test mode using a brake dynamometer to estimate performance drop of brake pads under the circuit driving condition. AUDI R8 with cast iron disc brake system is used as the reference vehicle. Brake pad performance drop is characterized by driving vehicle on F1 circuit, performing a subjective and objective evaluation of the brake performance, analyzing the evolution of the significant parameters related with brake performance drop. Taking into account all the data and information gathered in vehicle test, a well correlated brake pad lab test mode is developed.
\end{abstract}

\section{Key words: Brake pad, Lab test mode, Brake dynamometer, Performance drop, Circuit driving condition}

\section{INTRODUCTION}

As the kinetic energy of the vehicle is converted and dissipated into heat energy through the brake system, the vehicle decelerates [1]. The high speed vehicle needs high thermal energy because of the large kinetic energy for braking, this cause high temperature rise of the brake system. Therefore, the brake system for highspeed vehicle must ensure braking stability at high temperatures. In particular, the disc temperature rises to about $600{ }^{\circ} \mathrm{C}$ or higher at the time of traveling the circuit, and the fading phenomenon is frequently occurred in which the frictional coefficient between the disc and the pad is lowered due to the high temperature and the braking force is weakened. Due to such a mechanism, disc and pad's temperature is a key factor for the drop of the friction coefficient of the pad. Also, theoretically, it is known that the braking pressure, torque, and accumulated power also affect the friction coefficient's variation [2].

Brake dynamometer testing is helpful for reproducing brake component performance without the need to have the whole vehicle. The output from dyno testing must ensure the reliability of the results compared with the full-vehicle activities; therefore it is required to verify a good correlation.

In this study, it is assumed that the key factors affecting on the variation of friction coefficient between disc and pad are disc temperature and accumulated power by referring to Jung's study [3]. Brake pad's performance is tested using Audi R8 with cast iron brakes in Castelloli circuit . The brake pad performance drop is characterized by driving the vehicle on Castelloli circuit, performing a subjective and objective evaluation of the brake performance, analyzing the evolution of the key parameters. The results obtained in the circuit are correlated with dyno results. Taking into account the test results, well correlated brake pad lab test mode is generated.

\section{VEHICLE TEST in CIRCUIT}

Figure 1 shows measurement set-up of AUDI R8. GPS, gyro, brake pressure and disc and pad temperature sensors were equipped. Wheel Force Transducer(WFT) cannot be attached on the vehicle because WFT is very weaken with temperature rise. So, during actual vehicle driving on the circuit, the drop of friction coefficient of

Corresponding Author: Tae Kwan Son, Keimyung University, 1905, Dalgubeol-daero, Dalseo-gu, Daegu, 42601, Republic of Korea., +82535805347 . 
brake pad cannot be measured. Only driver's feeling(Subjective evaluation) and temperature rise of disc(Objective evaluation) are used to estimate brake performance drop. The professional driver drives the vehicle with its maximum performance for 20 laps. After 20 laps, tire and brake's performance decreases and lab time increases, then the test is stopped.
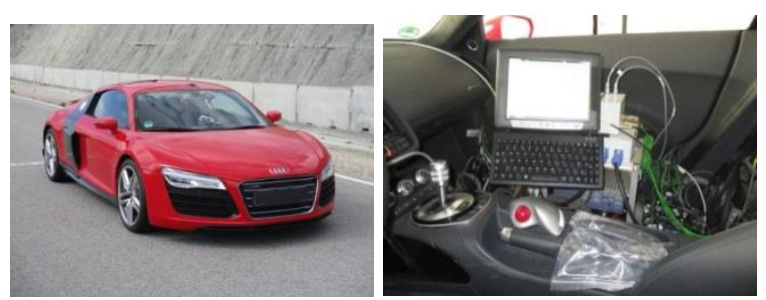

Fig 1 Measurement set-up for circuit driving

Figure 2 shows lab time variation. Lab time increases from $1^{\text {st }}$ lab to $6^{\text {th }} l a b$, then the lab time is remained at a certain level. This means that brake performance drop occurs during $1^{\text {st }}$ to $5^{\text {th }}$ lab. During this stage, brake friction coefficient may be changed in fast. After $7^{\text {th }}$ lab, the friction coefficient may keep a certain level, and this make the driver stable driving.

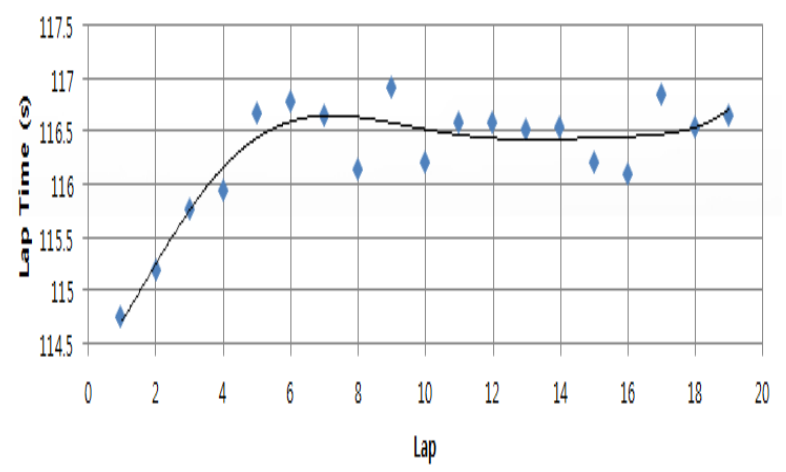

Fig 2 Lab time variation

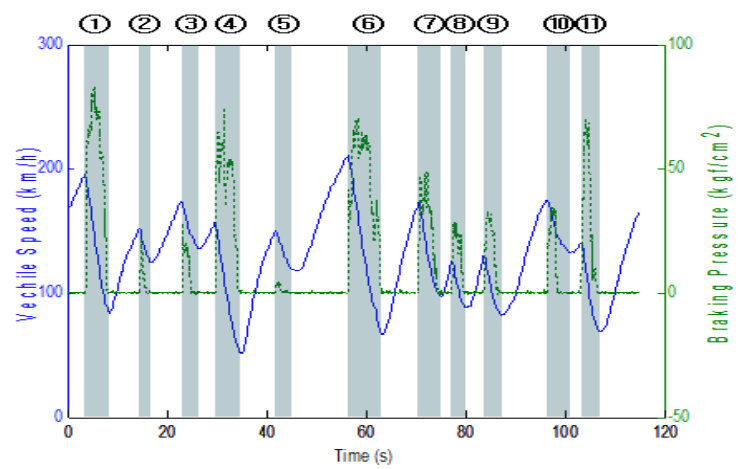

Fig 3 Vehicle speed and pressure variation at $1^{\text {st }}$ lab
Figure 3 shows vehicle speed and brake pressure variation at the first lab which shows the lowest lab time. There are 11 brakings and maximum speed is 210 $\mathrm{km} / \mathrm{h}$.

\section{LAB TEST MODE GENERATION}

Test Mode generation

Braking energy is calculated as follows.

$$
E_{B}=\frac{1}{2} m_{v}\left(v_{i}^{2}-v_{f}^{2}\right)
$$

where $E_{B}$ is the braking energy, $m_{v}$ is the vehicle mass, $v_{i}$ and $v_{f}$ are initial and final speed at braking region, respectively.

Accumulated power is calculated as follows.

$$
P_{A c c}=\sum \frac{\partial E_{B}}{\partial t}
$$

where $P_{A c c}$ is the accumulated power, $t$ is the braking time.

Table 2 shows the braking energy and cumulative operating rate calculated based on the initial speed, final speed and braking time of 11 braking sections. In Table 2, the total braking energy generated during braking process 11 was $14.57 \mathrm{MJ}$, with a braking energy of $1.32 \mathrm{MJ}$ per cycle.

\begin{tabular}{|c|c|c|c|c|c|}
\hline No. & $\begin{array}{l}\text { Initial } \\
\text { speed } \\
(\mathrm{km} / \mathrm{h})\end{array}$ & $\begin{array}{l}\text { Final } \\
\text { speed } \\
(\mathrm{km} / \mathrm{h})\end{array}$ & $\begin{array}{c}\text { Braking } \\
\text { time } \\
(\mathrm{s})\end{array}$ & $\begin{array}{c}\text { Braking } \\
\text { energy } \\
(\mathrm{MJ})\end{array}$ & $\begin{array}{l}\text { Accumulated } \\
\text { power } \\
\text { (MW) }\end{array}$ \\
\hline 1 & 196 & 80 & 4.53 & 2.31 & 0.51 \\
\hline 2 & 152 & 118 & 1.78 & 0.66 & 0.37 \\
\hline 3 & 170 & 126 & 2.35 & 0.94 & 0.40 \\
\hline 4 & 165 & 48 & 4.35 & 1.80 & 0.41 \\
\hline 5 & 149 & 104 & 3.01 & 0.82 & 0.27 \\
\hline 6 & 210 & 66 & 6.47 & 2.87 & 0.44 \\
\hline 7 & 171 & 94 & 3.53 & 1.47 & 0.42 \\
\hline 8 & 125 & 86 & 2.38 & 0.59 & 0.25 \\
\hline 9 & 129 & 73 & 2.77 & 0.82 & 0.29 \\
\hline 10 & 172 & 125 & 2.97 & 1.01 & 0.34 \\
\hline 11 & 146 & 60 & 2.68 & 1.28 & 0.48 \\
\hline \multicolumn{4}{|c|}{ Total } & 14.57 & 4.19 \\
\hline \multicolumn{4}{|c|}{ Average } & 1.32 & 0.38 \\
\hline
\end{tabular}

Table 1 Braking energy and accumulated power 
Vehicle mass is $1,870 \mathrm{kgf}$, average braking speed is $125 \mathrm{~km} / \mathrm{h}$ and average braking energy is $1.32 \mathrm{MJ}$. Using this coefficients, braking energy equation is converted as follows.

$$
\begin{aligned}
& 1.32(\mathrm{MJ})=1 / 2 \times 1870(\mathrm{kgf}) \times \\
& {\left[(125(\mathrm{~km} / \mathrm{h})+\mathrm{X})^{2}-(125(\mathrm{~km} / \mathrm{h})-\mathrm{X})^{2}\right]}
\end{aligned}
$$

where $\mathrm{X}$ is the speed variation.

From the above equation, $\mathrm{X}$, which is the deviation of the initial braking speed from the final speed, is calculated as $34 \mathrm{~km} / \mathrm{h}$, which is $1.32 \mathrm{MJ}$ when the initial braking speed is $159 \mathrm{~km} / \mathrm{h}$ and the final braking speed is $91 \mathrm{~km} / \mathrm{h}$. On the other hand, when the average cumulative durability during one braking operation is $0.38 \mathrm{MW}$ and the average braking energy during the one braking operation is $1.32 \mathrm{MJ}$, the average braking time during one braking operation is converted to 3.48 s. If the speed is reduced from $159 \mathrm{~km} / \mathrm{h}$ to $91 \mathrm{~km} / \mathrm{h}$ for $3.48 \mathrm{~s}$, the average deceleration becomes $0.55 \mathrm{~g}$. Based on the above calculations, a dynamo test mode as shown in Figure 4 was created. The sum of the braking energy generated when the condition of Figure 4 is repeated 11 times is equal to the sum of the braking energy generated by one wheel of the circuit.

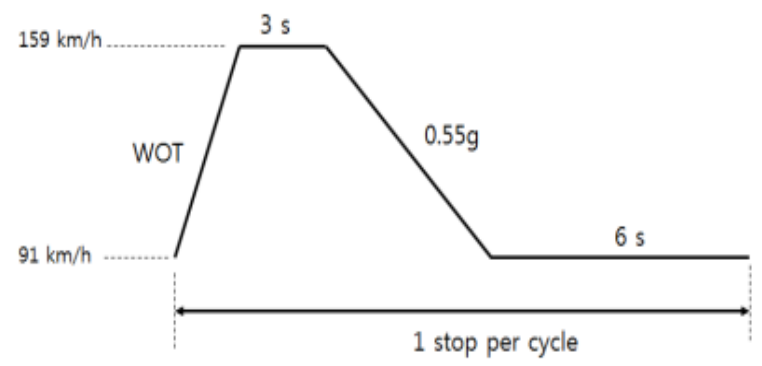

Fig 4 High speed fade test mode using brake dynamometer

\section{Cooling Effect Adaptation}

The completion of the test mode generation provides a dynamometer procedure which includes all parameters to perform the test except for the vehicle cooling simulation. The test mode takes into account the lap braking power, which is one of the main factors affecting the braking performance behavior; but the second variable, which was the disc temperature, needed to be considered as well and it justifies the cooling set up procedure.

The aim was to achieve a dyno air flow speed which could simulate the actual vehicle cooling. As the relationship between the speed and the cooling exists and the vehicle velocity during a circuit driving lap is continuously changing, it was approximated by calculating the simulated vehicle cooling at the average dyno testing speed. Knowing the vehicle cooling at a specific speed allows setting up the right air flow speed to meet it.

Reference vehicle data is required for the calculations; in that case the cooling at three different speeds (100 $\mathrm{km} / \mathrm{h}, 150 \mathrm{~km} / \mathrm{h}$ and $200 \mathrm{~km} / \mathrm{h}$ ) was acquired to be able to simulate the temperature behavior at any other required velocity. Additional information regarding the brake rotors geometry and characteristics was also needed to proceed with the simulation.

The cooling coefficient for each of the vehicle cooling test speeds can by calculated by iterating according to Newton's cooling law for heat transfer.

$$
-\frac{h A}{m C_{p}}\left(T-T_{\infty}\right)=\frac{\partial T}{\partial t}
$$

where $h$ is the heat transfer coefficient, $A$ is the swept area, $m$ is the disc mass, $C_{p}$ is accumulated power, $T$ is the initial temperature, $T_{\infty}$ is the ambient temperature, $\partial \mathrm{T}$ is the temperature variation and $\partial \mathrm{t}$ is the time variation.

The vehicle cooling coefficient was calculated taking into account the individual cooling coefficient from each of the three vehicle speeds considered and based on an empirical equation which determines that the coefficient can be assumed as a speed function $\mathrm{h}(\mathrm{v})$ represented by dimensionless numbers as follows

$$
h_{\text {final }}=h_{\text {ref }}+\alpha \times V^{n}
$$

where $\alpha$ and $\mathrm{n}$ are dimensionless numbers and $V$ is the vehicle speed.

The simulated vehicle cooling coefficient was used to calculate the cooling time required to cool down the brake discs from a temperature range (considered by the user) which equals the actual vehicle cooling at the average dyno testing speed. The time is the output information required to set up the air flow velocity for the dynamometer as shown in Figure 16

\section{PARAMETER STUDY}

In the test mode created in the previous section, the frontal braking system of the AUDI R8 AUDI R8 V10 coupe was evaluated and the results were analyzed. In 
the initial bedding step, the process of decelerating from $80 \mathrm{~km} / \mathrm{h}$ to $0.3 \mathrm{~g}$ at $30 \mathrm{~km} / \mathrm{h}$ was repeated 50 times with the disk surface temperature being $100^{\circ} \mathrm{C}$. The test mode shown in Fig. 4 is repeated 40 times in total, which is equivalent to running the circuit about 3.4 times. No cooling condition is applied in this teset.

Figure 5 (a) shows the result of temperature rise of disk and pad according to repetitive braking. The disk temperature was measured using a rubbing thermocouple as shown in Figure 5 (b), and the pad temperature was measured by inserting a thermocouple inside the pad. In Figure 5 (a), the disk temperature converges to about $780^{\circ} \mathrm{C}$ from about 25 times after the braking point, while the pad temperature continues to rise. This is due to the fact that the thermocouple inserted into the pad due to pad wear comes close to the disk to be. Compared to the pad, the disk is relatively much less wearable, so a relatively stable temperature measurement is possible. Therefore, in this study, disk surface temperature is used as a representative value of braking temperature.

Figure 6 (a) shows the variation of friction coefficient according to braking pressure and Figure 6 (b) shows variation of friction coefficient according to braking torque. In order to maintain the deceleration of $0.55 \mathrm{~g}$, the braking torque is controlled to be constant. In Figure 6 (b), the braking torque is controlled in the range of $1,500 \mathrm{Nm}$ to $1,600 \mathrm{Nm}$. Figure 4 (c) shows changes in coefficient of friction with changes in disk temperature. When the temperature is about $300^{\circ} \mathrm{C}$, the coefficient of friction reaches a maximum value of about 0.45 , which is constant up to $550^{\circ} \mathrm{C}$. After that, the coefficient of friction decreases sharply and decreases to below 0.35 in the temperature range above $750{ }^{\circ} \mathrm{C}$. The high temperature fade region is defined as the interval at which the friction coefficient is drastically lowered at a temperature higher than $550^{\circ} \mathrm{C}$. In this region, the slope of the lowering of the friction coefficient is maintained smoothly. Is a characteristic required for a highperformance brake pad.

Figure 4 (d) is the coefficient of friction change according to cumulative uniformity. As the constant braking of Figure 2 is repeated, the cumulative uniformity increases linearly and the friction coefficient gradually decreases. The coefficient of friction is increased to the point where the cumulative uniformity reaches $1 \mathrm{MW}$ ( 3 times braking point), and then the friction coefficient is maintained at 0.35 or higher until cumulative uniform 1MW (11 times braking point). After that, the coefficient of friction decreases, and after $13 \mathrm{MW}$ cumulative coefficient, the friction coefficient is decreased to the level of 0.25 . Since the 11th braking is the same as the braking energy generated when the vehicle is driven by one wheel of the circuit, Figure From the result of 4 (d), it is expected that the braking performance is lowered after driving the circuit one time and the braking force is low because the coefficient of friction is as low as about 0.25 after about three times of running (cumulative uniformity of $13 \mathrm{MW}$ ). Based on the above analysis results, disk temperature, braking pressure, and cumulative uniformity were selected as factors affecting the friction coefficient.

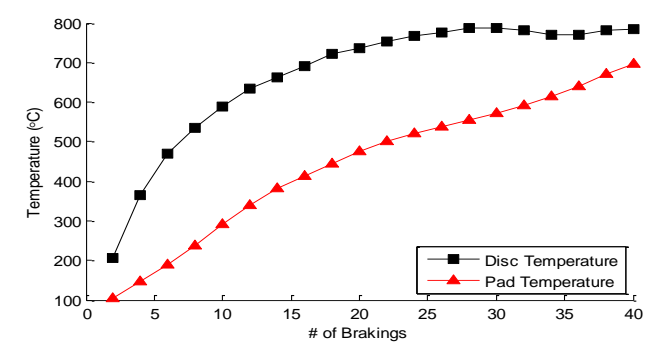

Fig 5 (a) Temperature rise of disc and pad

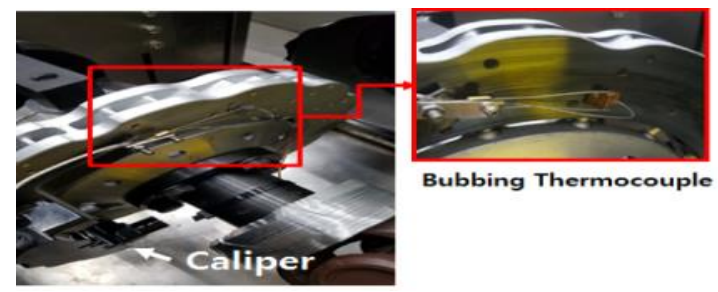

Fig 5 (b) Measurement set-up of disc temperature

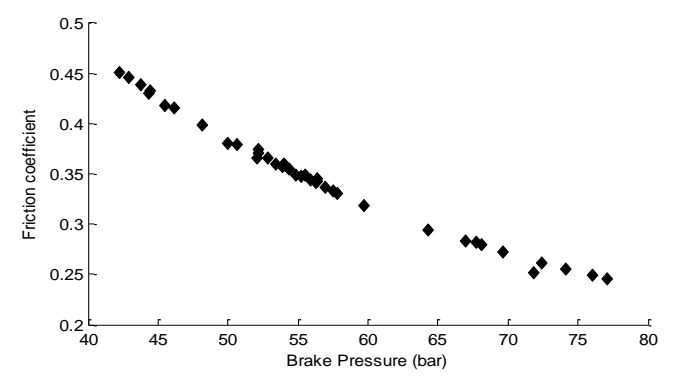

Fig 6 (a) Friction coefficient variation according to brake pressure

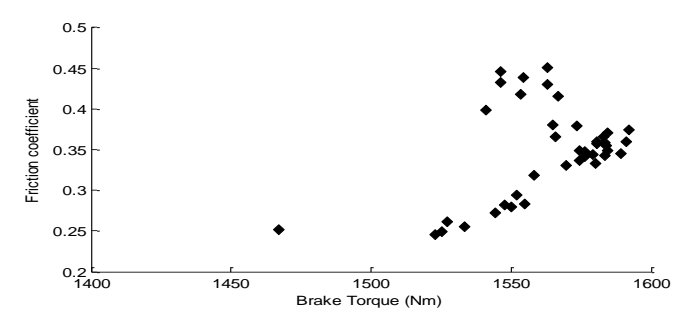

Fig 6 (a) Friction coefficient variation according to brake torque 


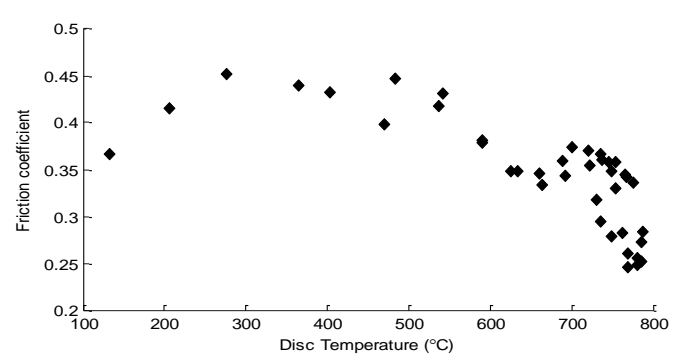

Fig 6 (b) Friction coefficient variation according to disc temperature

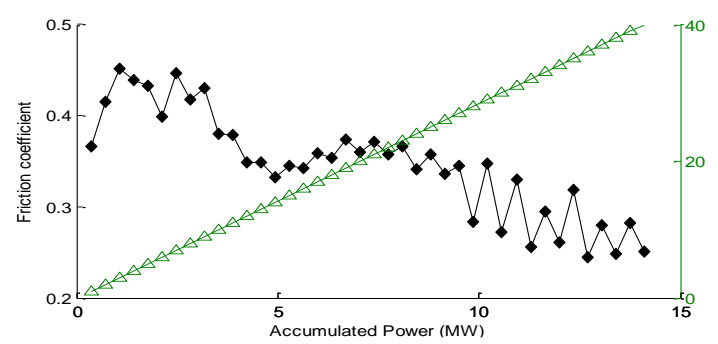

Fig 6 (c) Friction coefficient variation according to accumulated power

\section{VALIDATION OF TEST MODE}

Figure 5 shows disc temperature comparison. Increasing tendency is very similar between dyno and vehicle test result, and also final temperature remains similar levels. Temperature of disc increases until number of brakings is over 50 . This means that brake friction coefficient may changes by $50^{\text {th }}$ brakings, and then it remains certain level. 11 brakings equals to 1 lab. Therefore, brake performance drop seems to be

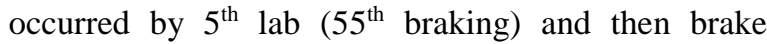
performance may be stable. This phenomena is the same with the subjective test result shown in figure 2 .

The second output being compared is the accumulated power during braking; the correlation was also achieved by comparing dynamometer trials \#1 and \#2 and actual Castelloli circuit data as shown in Figure 6.

The braking performance is also compared by plotting the friction coefficient $\mu$; in that case the graph (Figure 7) shows the objective comparison between trial \#1 and trial \#2 values and an overlay of the subjective evaluation of the brake performance done at Castelloli circuit. It must be remarked that the friction coefficient was not objectively measured during Castelloli circuit testing as the WFT sensors cannot be attatched. The vehicle subjective evaluation done by the driver during Castelloli circuit test was indicating an interval with no notable performance drop (green area), an interval where the brake performance decreases to a notable level (yellow area) and an interval where no more noticeable drop is recognizable by the driver (red area). The friction coefficient behavior follows the same shape during the first brake applications when the brake pad is performing well.

Once the drop starts to appear the $\mu$ behavior between trial \#1 and \#2 differs because test mode severity were differed. At trial \#1, cooling effect is more severe than trail \#2, and this cause trial \#1 causes faster performance drop tendency. Figure 7 shows how the brake performance drop remarked by the drivers meets the area where the friction coefficient drops below the acceptance mu value for the brake pad type.

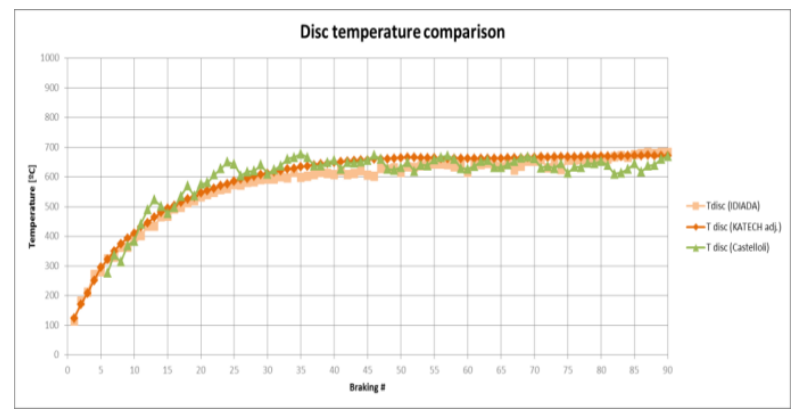

Fig 5 Front disc brake temperature comparison

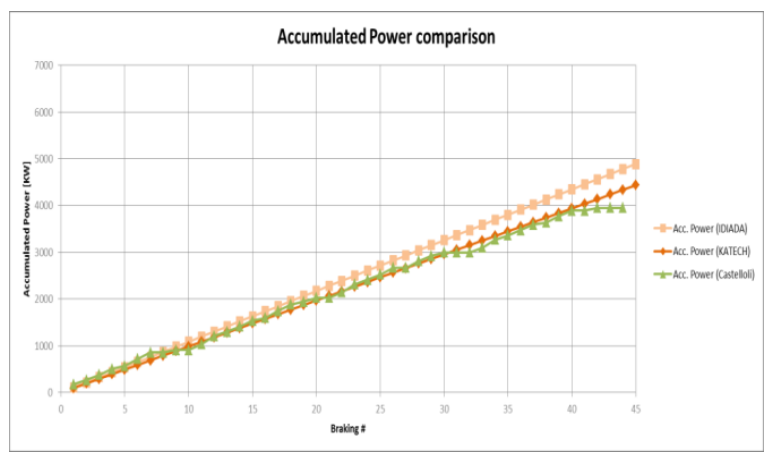

Fig 6 Accumulated braking power comparison

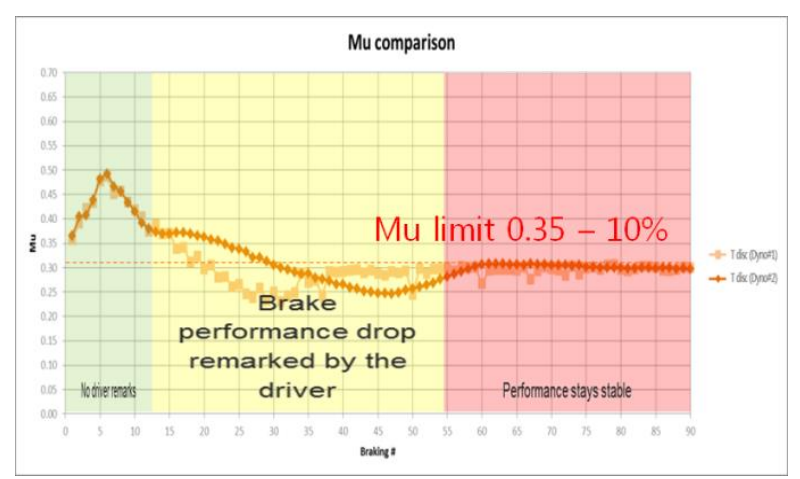

Fig 7 Friction coefficient comparison 


\section{CONCLUSION}

In this study, the brake lab test mode was developed to estimate brake performance drop under circuit driving condition. Vehicle test using AUDI R8 with cast iron brakes was done in Castelloi circuit. Simple measurement system was equipped, and vehicle speed and disc temperature data was used to generate test mode. The trial \#1 and \#2 which have different braking and cooling mechanisms shows different results. Trial \#1has more braking severity than actual vehicle test, and Trial \#2 was generated. Trial \#2 shows similar disc temperature rise tendency with Trial \#1, but Trial \#2 shows better correlation with subjective vehicle test result.

\section{ACKNOWLEDGMENTS}

This work was supported by the Technology Innovation Program(10076592, Development of high performance and noise-free material for multi piston caliper to meet global environmental regulation) funded by the Ministry of Trade, Industry \& Energy(MOTIE, KOREA)

\section{REFERENCES}

[1] Hwang, P., Wu, X. and Jeon, Y., 2008. epeated Brake Temperature Analysis of Ventilated Brake Disc on the Downhill Road. SAE Technical paper.

[2] Limpert, R. 1999. Brake Design and Safety. SAE International, USA

[3] Jung, S. P. and Park, H. B., 2018, Analysis of Influence Parameters for Brake System's Performance during High Speed Braking, Transaction of the Korean Society of Automotive Engineers, 26(2), 196-201. 